\title{
A POTÊNCIA DO CORPO E DA CORPOREIDADE NAS PRÁTICAS E VIVÊNCIAS EDUCATIVAS
}

\author{
Mariana Alonso López-López ${ }^{\mathrm{i}}$ \\ Graciele Ribeiro Galdino ${ }^{\text {ii }}$
}

\begin{abstract}
Resumo: Todo corpo carrega em sua história marcas e saberes advindos de sua trajetória. Todas essas informações se movem em sintonia com a corporeidade do ser. O presente artigo tem por objetivo refletir sobre a importância da liberdade corporal nas escolas, bem como falar do expressar-se e descobrir-se em suas múltiplas linguagens no processo de ensinoaprendizagem. Estar aberto a observar sem interferir é o modo como escolhemos perceber de que forma o que acontece espontaneamente, e que escapa ao escopo do planejamento pedagógico, pode nos ajudar a dar passos na direção de uma educação mais potente e menos opressora. Acreditamos que é a partir da conscientização sobre uma corporeidade capaz de falar sem necessariamente precisar usar palavras, que professores e alunos podem encontrar caminhos para uma educação mais viva e que vá além da sala de aula.
\end{abstract}

Palavras-chave: Corpo; Potência; Educação; Práticas Pedagógicas.

\section{LA POTENCIA DEL CUERPO Y DE LA CORPORALIDAD EN LAS PRÁCTICAS Y VIVENCIAS EDUCATIVAS}

Resumen: Todo cuerpo carga en su historia, marcas y conocimientos adquiridos en su trayectoria. Todas estas informaciones se mueven en sintonía con la corporalidad del ser. Este artículo tiene como objetivo reflejar la importancia de la libertad corporal en los colegios, así como hablar de la propia expresión y autoconocimiento en todas sus formas en el proceso de enseñanza-aprendizaje. Estar dispuesto a observar sin interferir, es cómo escogemos percibir cómo lo que acontece espontáneamente y que escapa a la planificación pedagógica, nos puede ayudar a dar pasos en la dirección de una educación más potente y menos opresiva. Creemos que a partir de la concienciación sobre una corporalidad capaz de hablar sin necesariamente utilizar palabras, es como profesores y alumnos pueden encontrar caminos para una educación más viva y que va más allá del aula.

Palabras clave: Cuerpo; Potencia; Educación; Prácticas Pedagógicas.

\section{Introdução}

Encontramo-nos muitas vezes oscilando ao sabor das ondas. [...] Vagamos, vulneráveis, oscilando entre o medo e a esperança. Acompanhamos a maré imaginando, ora o pior, ora o melhor. A incerteza e a finitude são premissas que não podemos suprimir, são as condições de estarmos navegando (RAZÃO INADEQUADA, 2018).

2020 López-López; Galdino. Este é um artigo de acesso aberto distribuído sob os termos da Licença Creative Commons Atribuição Não Comercial-Compartilha Igual (CC BY-NC-4.0), que permite uso, distribuição e reprodução para fins não comerciais, com a citação dos autores e da fonte original e sob a mesma licença. 


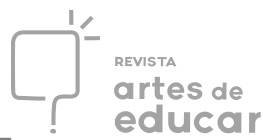

Esta pesquisa traz a questão da corporeidade dentro das instituições de ensino e uma inquietação sobre a imobilidade dos corpos entre carteiras, hierarquias e normas. Com o olhar voltado para as ações corporais de professores e alunos no ambiente escolar, utilizaremos os conceitos de vivência e experiência a partir da obra de Vigotski (1999) encontrada em Roberti (2019).

A ideia de vivência compreende percepções e traços constitutivos de cada indivíduo envolvido em uma ação criadora e as particularidades que emergem a partir de suas relações com o meio. Para Roberti (2019), muitos pesquisadores acreditavam que o conceito de vivência mantinha uma base interacionista. Porém, estudos mais aprofundados nos levam a crer que Vigotski (1999) acreditava na unidade da construção de personalidades juntamente com o desenvolvimento motor do corpo.

O conceito russo de Perejivanie, (vivência em português) resulta no uso consciente do Opit (experiência em português) no ato de criação. A concepção de experiência aqui, se refere às possibilidades de interpretação e aos acúmulos psicossociais e materiais que constituem as atividades humanas (ROBERTI, 2019).

Conforme Santos (2019, p.28) "Sobrevivemos, como humanidade, pela nossa capacidade de cooperação e empatia”. Quando se pensa no quanto o corpo humano se revela nas tarefas e afazeres do cotidiano, passamos a entender melhor como ele se comunica. Neste corpo, existem marcas positivas e negativas impressas pelas experiências da vida. Professores e alunos trazem em seus corpos suas tensões, alegrias, razões e subjetividades.

Ainda citando Santos (2019, p. 28), "[...] uma linguagem mais consciente e conectada à nossa essência compassiva diminui as resistências". A percepção da forma como o corpo resiste, reage e se estabelece em seu meio, permite compreender melhor quem são esses corpos que habitam a escola e nos faz refletir sobre as limitações de nosso sistema educacional.

Como sujeitos sensíveis, devemos entender o aprender como um processo capaz de fazer vibrar a potência inerente à natureza humana. A partir da metodologia observacional, buscamos entender como os corpos se relacionam na escola, como se posicionam e como entram em contato com o ambiente escolar.

O corpo neste estudo é tido como um lugar potente de comunicação e descobertas. É essa potência que se mostra ao mundo, quando possuímos liberdade de movimento e estamos abertos às experiências sensíveis. Os gestos de um corpo estão em sintonia com tudo que o 


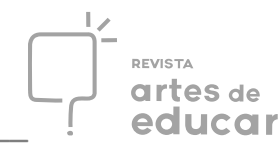

atravessa. Observar e ampliar o olhar para a forma como se estabelece a dinâmica entre esses corpos de natureza multifacetada e pluridimensional em espaços de aprendizagem é a proposta desta pesquisa.

\section{O corpo para além da dimensão biológica}

Ao longo da história, várias visões de corpo foram concebidas e se alteravam de acordo com a época de seus pesquisadores. Para Aristóteles, o corpo era "um instrumento da alma" (Aggio, 2009, p. 78) e para Descartes (1983) havia uma separação entre o corpo e a alma, fundado na concepção de corpo-máquina. "Eu sou um ser que pensa. Proclamou-se assim o divórcio entre o pensamento e o ser, a ruptura ontológica do ser e a lógica do pensamento" (RIOS, 2015, p.52). Porém, o corpo vai muito além de um objeto a ser estudado. Sua pluridimensionalidade é "a presença e materialização da vida humana, vivida de forma subjetiva, complexa e difusa pelos sujeitos que o "habitam" de forma concreta e dinâmica” (TALOMONI, 2009, p.2).

O corpo humano, conforme Merleau-Ponty (1996), precisa ser pensado no ato educativo devido à duas condições essenciais: uma é a capacidade que o corpo tem de proporcionar autoconhecimento e autocuidado; a segunda é a sua condição singular de produtor de conhecimento. Porém, ao situar o corpo na educação, Nóbrega (2008) declara que a escola tem negligenciado a importância do corpo, tornando-o apenas uma exclusividade das aulas de Educação Física. É a partir da expressividade corporal do aluno, que toda a sua dimensão cognitiva e afetiva é revelada, transformando o corpo em um lugar estratégico onde o saber pode acontecer a partir do pensar e do sentir.

Le Breton (2006), também acredita que o corpo existe para além de sua dimensão biológica, direcionando nosso olhar para o fato de que o pertencimento social se constitui a partir do mover, entre sentimentos, percepções e sensações de um corpo inserido em determinada cultura. Portanto entende-se que para educar, é necessário refletir sobre o binômio corpo e mente, pois não se pode separar o intelecto humano das dimensões corporais, emocionais e até mesmo espirituais.

Para Freire (1991), o corpo é a prova mais concreta da nossa percepção de realidade e a motricidade é aquilo que testifica a condição de existência do corpo. Sendo assim, podemos dizer que a forma como um corpo se move, deixa transparecer o seu estar no mundo. A ideia 
de separação entre sentimento e racionalidade precisa ser ultrapassada nas práticas pedagógicas. Alguns teóricos já trazem a ideia de que tudo está interligado dentro de um mesmo ser, que este ser também é corpo em movimento e que o movimento deste corpo mostra como esse ser reage em relação ao processo de aprendizagem pelo qual está passando:

O corpo não se constitui meramente num objeto ou conteúdo a ser explorado, mas antes a um sujeito humano, e a relação entre aquilo que se ensina e o que se aprende sobre o corpo na educação formal tem implicações na corporeidade dos indivíduos. Se estes indivíduos, de certa forma, são incitados a viverem seus corpos como "uma grande máquina humana", em detrimento de suas experiências pessoais ou sociais, este processo acarretará também em influências e consequências para a formação das identidades (MACEDO, 2005, p.137).

Não basta pensarmos apenas no corpo. A corporeidade perpassa a prática docente e também as relações emocionais e sociais entre professores e alunos.

A corporeidade implica, portanto, na inserção de um corpo em um mundo significativo, na relação dialética do corpo consigo mesmo, com outros corpos expansivos e com os objetos do seu mundo (ou as "coisas" que se elevam no horizonte de sua percepção). O corpo se torna a permanência que permite a presença das "coisas mesmas" manifestar-se para mim em uma perspectividade; torna-se o espaço expressivo por excelência, demarca o início e o fim de toda a ação criadora, o início e o fim de nossa condição humana. Mas ele, enquanto corporeidade, enquanto corpo vivenciado, não é o início nem o fim: ele é sempre o meio, no qual e através do qual o processo de vida se perpetua (OLIVIER, 1995, p.60).

A pergunta que fica é: como essas relações corporais são construídas, sendo o corpo tão negligenciado na escolarização? Pouco se fala sobre a potência do corpo do docente enquanto veículo de comunicação e sobre as possibilidades que os corpos de seus alunos podem trazer à tona. É preciso, conforme Vianna e Castilho (2002, p. 27-28):

[...] estar atento à percepção do corpo dos alunos, saber estimular sua presença, estimular o aprendizado através do corpo. Porque o corpo é capaz de aprender tanto quanto de criar. Usar o corpo dos jovens pode ser uma bela maneira de estimular-lhes a liberdade e a criatividade, porém mais ainda - pode ser uma ferramenta muito eficaz para a transmissão dos conteúdos.

Conforme Moyzés e Mota (2004), toda história de vida de qualquer indivíduo fica marcada no corpo e essas marcas podem ser perceptíveis tanto na corporeidade do professor quanto do aluno. Para Rodrigues (2001) todas as tensões, anseios e apreensões dos alunos e 


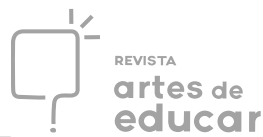

professores passam pelo corpo. Dessa forma é impossível pensar em aprendizagem se abdicamos ou negligenciamos a potência que o corpo evoca.

O corpo pode se tornar um grande aliado da educação em contextos de sala de aula. Afinal, é a partir da capacidade comunicativa do corpo, que podemos ser beneficiados com práticas pedagógicas que sejam capazes de sensibilizar. É através da conscientização de que corporeidade e motricidade andam juntas, que o docente pode propiciar um ambiente favorável para que a aprendizagem possa acontecer sem violência. "Um olhar cuidadoso pode nos mostrar o quanto somos corresponsáveis pelos problemas que enfrentamos diariamente" (SANTOS, 2019, p.27).

\section{Que corpos habitam a escola?}

Quando se pensa em corpo na escola é importante entendê-lo enquanto sujeito. Os corpos-sujeitos, não são apenas um conjunto de articulações anatômicas e fisiológicas. Eles abarcam a nossa dimensão enquanto indivíduos e representam nossas subjetividades, psiques e histórias (FREGONEIS 2018).

Conforme Gaia (2006) o corpo ainda está atrelado ao campo da pedagogia racional, pois até mesmo nas atividades lúdicas, o sujeito-corpo ainda é disciplinarizado ou limitado. Ainda segundo o autor, “o corpo não vai à escola” (p. 251) e isto registra a falta de interesse epistemológico deste assunto no campo educacional, principalmente no que tange as possibilidades de um corpo em aprendizagem.

Para Inforsato (2006), o sistema que mais cooperou para o desenvolvimento e divulgação do racionalismo cartesiano foi o sistema educacional. Isso nos leva a pensar nas demarcações à que este corpo é submetido dentro das instituições de ensino, onde, em geral, a lógica do controle ainda vigora.

O corpo representa a nossa unicidade, mas também reflete nossas identidades singulares e individuais Há uma riqueza existente em todas as culturas e histórias que subsistem nos corpos que transitam pelos caminhos da educação. Entretanto, essa riqueza parece ser desperdiçada pelo planejamento engessado e completamente programado por um adulto, que esqueceu que um dia também foi aluno. O corpo é um território potente de criatividades e invenções, mas tanta necessidade de controle acaba por minar essa potência, que parece não ter autorização para existir frente à rigidez das regras. Sendo assim, nossos 
corpos, que deveriam ter liberdade e tranquilidade para se descobrir potentes, vão sendo silenciados e adormecidos, contrariando sua própria natureza:

Parece-nos que hoje o homem preocupa-se mais com seu corpo, em grande parte devido ao sistema social em que estamos inseridos, no qual há uma supervalorização do material além do sensível, do estético, do externo. Mas ainda com vestígios da mecanização, sendo uma realização "ocupar, como uma engrenagem, o lugar que lhe foi determinado no conjunto da grande máquina que é o universo. Seu supremo ideal é atingir o máximo rendimento e a máxima eficiência" (SANTIN, 2010, p. 62).

O pensamento educacional brasileiro vigente diz que um corpo inteligente é aquele que se deixa disciplinar. Por isso, a cultura corporal valorizada na escola é a dos " [...] movimentos que visam a prontidão: exercícios sistemáticos e mecânicos que tem o objetivo de aprimorar a coordenação motora [...]" (TIRIBA, 2017, p.5). Tudo isso fragiliza a potencialidade e o processo de desenvolvimento dos alunos.

Conforme Magrin (2016), desde o começo da história da educação, o corpo na escola sofreu rejeições, sendo o aspecto cognitivo tido como prioridade, compreendendo a cabeça como uma máquina apta a reproduzir qualquer tipo de ensinamento projetado. A história registra a escola como uma espécie de fábrica de cidadãos, que por meio de ensinamentos patrióticos, produtivos e políticos concebe o seu exército.

A escola precisa ser um espaço que abra oportunidades para manifestações livres, que propiciem a experiência da diversidade cultural. Somente através desta autonomia, os educandos são capazes de descobrir quem são e como lidar com conquistas e frustrações. Não há aprendizado dicotômico. Todo conhecimento é perpendicular ao corpo, pois é por ele que perpassam as inúmeras formas de se expressar e comunicar. É preciso que um novo olhar sobre o corpo seja concebido na escola, a fim de que ele possa ser sentido e entendido, como um lugar de construção de identidades, conhecimentos e movimentos de vida.

\section{O corpo do professor}

Em linhas que defendem a leveza e uma educação para o sensível, Silva e Oliveira (2016, p.775) falam sobre a importância de se colocar como "um observador que se dá o tempo para a experiência". 


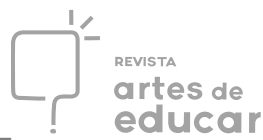

Em aceleração, nossos docentes cumprem suas tarefas automaticamente e sem muito tempo para perceber os detalhes e sutilezas do que está acontecendo no momento presente. É como quando uma criança puxa a barra da saia de um adulto pedindo atenção e a resposta que recebe é: - Espera que agora estou ocupada. E nessa ocupação constante, o olhar se perde e já não se volta na direção da criança que espera, espera, até o dia em que se cansa de esperar e não toca mais a barra de nenhuma saia, como se ali não houvesse espaço para ela existir.

Será que o mesmo acontece com os educadores em seu contexto de trabalho? Muitas sensações presentes nas experiências diárias se perdem pela falta de um olhar observador para as crianças, que tocam o corpo do professor de muitas formas, solicitam atenção, mas muitas vezes, este professor está ocupado demais para parar e perceber a presença da criança e atender suas demandas. Até que um dia, esse sentir, de tão ignorado, se acostuma à indiferença e o corpo passa a trabalhar como uma máquina: sem se ouvir, se conectar, se sentir...

Parar? Apenas quando o corpo adoece e, assim, nos resta pensar como vamos reparar o estrago. Infelizmente muitas vezes, o corpo não é escutado nem no adoecimento. A saúde se deteriora e é recuperada, retomando mais um ciclo de comportamentos mecânicos, de violência com o corpo e de sobrecargas impostas pelas pressões da vida contemporânea. A desmotivação para o trabalho e mais adoecimento podem ser consequência desse ciclo de precarização da presença corporal.

Por meio da Lei de Acesso à Informação 3 foram obtidos dados que nos mostram que "No ano passado (2018), a cada três horas, um professor da rede de ensino do Rio de Janeiro se afastou alegando problemas mentais". A Secretaria de Educação concebeu 3.055 licenças por problemas mentais e recebeu 29.495 atestados médicos solicitando afastamento de até seis dias por conta de distúrbios psicológicos.

A ação docente muitas vezes se dá no sentido de exercer poder sobre seus alunos; assim, as relações são desgastantes física e emocionalmente. O corpo está constantemente implicado nisso. Um corpo que também recebeu ordens passivamente, sujeito à hierarquias verticalizadas. Um corpo que precisa estar no controle e em produtividade. Um corpo que pouco se enxerga e que, assim, pouco enxerga o outro também. Sob pressão externa e interna, o corpo do docente vive as consequências de uma educação que sobrecarrega e leva ao limite tanto educadores quanto educandos. 


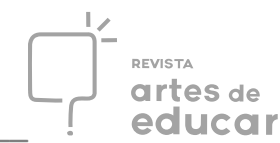

Sabe-se que existem as exceções. Educadores que em sua busca por um caminho prazeroso dentro da escola, já conseguem perceber seus alunos como parceiros de jornada e não como corpos-sujeitos onde depositam suas ordens, conhecimentos e expectativas. A realidade é que a maioria dos professores não percebe que seus alunos também podem contribuir com seu próprio crescimento profissional e continuam a insistir em uma metodologia de aprendizagem unilateral que empobrece a troca professor-aluno no dia a dia escolar.

Brandão (2010), nos chama atenção sobre a importância do diálogo e da participação de todos os envolvidos nos processos de ensino-aprendizagem: "Todo aquele que ensina aprende com quem aprende. Todo aquele que aprende ensina ao que ensina. Toda educação é uma vocação do diálogo” (p.106).

Aos olhos do pesquisador-observador, quando o professor planeja as vivências de forma coletiva e convida os alunos a participar da criação das atividades, seu corpo parece ficar mais leve no ambiente escolar. Ao observar os professores na escola, notamos que seus movimentos corporais são mais soltos e ele sorri mais quando a atividade não traz conflitos com os alunos. Nos momentos de construção coletiva, nos quais a responsabilidade é compartilhada, isso se torna mais evidente.

O professor possui uma formação que o autoriza a dar aulas, mas a forma como os conteúdos chegam aos alunos pode se dar por vias que ele jamais imaginou. Os próprios alunos podem levá-lo por esses caminhos de surpresa e descoberta, quando é permitido que eles sejam parte de seu processo de desenvolvimento.

Gordon (2015) traz essa questão do adulto estar atento para as contribuições da criança através da empatia: "Entrelaçando empatia e ética, podemos criar princípios morais que transpõem o vão entre nós e eles, de maneira que se torne natural identificar-se com os sentimentos dos outros e compreendê-los" (p.202).

A ideia aqui não é culpabilizar os professores. Somos produtos imersos em um sistema que vem abafando a imaginação e a criação, emparedando para controlar. Tiriba (2018, p.230) diz que "O estado de emparedamento que se efetiva nos espaços de cuidado e educação das crianças produz uma quebra do que é contínuo”, como o fluxo da vida. Como reinventar a formação docente e permitir que nossos futuros professores experimentem o que é estar "desemparedado", conscientes de que somos bastante influenciados por nosso processo formativo? De acordo com Tiriba (2018) “desemparedar" está relacionado ao compromisso 


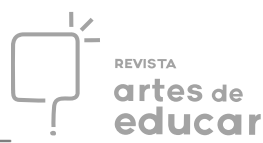

com a alegria, a integridade e o direto ao crescimento em liberdade entre terra, céu e água. Significa "[...]uma ação de resistência contra o isolamento da escola, lugar de transmissão exclusiva do saber legitimado como científico" (TIRIBA, 2018, p.227-228).

Para fazer diferente é preciso desconstruir modos de educar o menino ou menina, que ignoram seus sentimentos e desejos e aplicam punições arbitrárias, que, de fato, não cumprem função educativa, se pautando em rotinas repetitivas e sem sentido. Dimenstein; Alves (2008), acreditam que é preciso que nos vejamos como eternos aprendizes, para que possamos abrirnos para a possibilidade do encanto, tendo a paixão e a curiosidade como principais motores.

O professor também carrega as marcas de um sistema disciplinador de corpos. O corpo docente está tão preso quanto o corpo de seus alunos. São reféns de uma metodologia obsoleta que vem sendo reproduzida ao longo dos anos sem conseguir se transformar.

Para que haja mudanças e transformações, os professores precisam permitir-se ao que hoje é considerado um atrevimento: dar aos seus alunos o direito de existir e encarar suas vivências como seu melhor material de referência.

É preciso encontrar o lugar onde a coragem desperte e acorde também a ousadia. Assim, é possível voltar a acreditar que existe um caminho possível para uma educação mais humana, onde a escola acolha com sensibilidade e esteja aberta e atenta à observação dos corpos que caminham por ela.

\section{O corpo do aluno}

“Aprende-se silenciosamente”, diz Almeida (2009, p.3). O corpo do aluno é treinado para obedecer as ordens de alguém "mais forte". Desde cedo aprende que caso não o faça, sofrerá algum tipo de punição. O sistema de poder é reproduzido na escola. Corpos cheios de autoridade pela posição hierárquica que ocupam no campo de forças da educação, atuam sobre corpos apassivados, sem voz e submetidos a um funcionar como engrenagens. Assim, o corpo aprendiz ao invés de potencializar, despotencializa e até silencia, se torna invisível.

Trabalham todos, alunos e professores, na esteira de produção que nos faz atuar como máquinas de resultado, sem que tenhamos consciência de nossa humanidade triturada. $\mathrm{O}$ professor está apenas cumprindo o seu papel de acordo com a formação que recebeu e o 


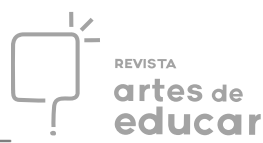

aluno, aprendendo sobre as vantagens da obediência, enquanto sua potência se apaga sem saber como atravessar as vontades negadas de um corpo preso à uma carteira.

Ao olhar o aluno, os professores poderiam se perguntar: Que desejos tem esses sujeitos-corpos? O que eles estão tentando me dizer com os movimentos imprevistos em meio aos permitidos?

O corpo de nossos alunos tem vontade de vida. Mas se pensamos nas imagens que seus corpos desenham nos espaços escolares, vamos ver que parecem mais corpos à deriva. Os pensamentos movem os corpos de acordo com a emoção que sentem. Damásio (2004, p.69) reforça essa questão ao dizer que “[...] os sentimentos são constituídos, sobretudo, pela percepção de um certo estado do corpo [...]".

De alguma forma os corpos dos alunos ainda tentam resistir. Se movem, produzem o imprevisto, se manifestam, tentam nos contar sobre eles. Mas o tempo na escola não coloca o tópico (prestar atenção nas reações dos alunos ao que é proposto) no planejamento recheado de conhecimentos pedagógicos. Fica claro que o encontro que se desenha entre esses corpos "grandes" e "pequenos" apresenta conflito mais do que prazer.

A escola deveria ser o lugar em que a criança pudesse experimentar o respeito e a afetividade, convivendo com gente disposta a escutá-la, que apostasse nela e a auxiliasse na busca e no desenvolvimento de suas habilidades (MARTINS, 2014, p.106).

Nossos alunos estão inquietos, tentando entender porque tantos "NÃOS" em meio à tanta vontade de experimentar o mundo.

[...] o corpo se silencia diante da redução das experiências que a educação formaliza e institucionaliza. Não somente porque a escola é um lugar proposital de silenciamento do Corpo, mas porque o Corpo entendeu o quanto os anticorpos educacionais não serão vencidos se ele falar. Ele se cala, portanto (ALMEIDA, 2009, p.7).

Quando o professor se preocupar menos com os conteúdos a ensinar e olhar para o aluno como alguém para construir junto, o aluno começará a descobrir que em seu corpo existem outras partes, não somente cabeça. O corpo, em sua inteireza, não pode ser negligenciado em ambientes de aprendizagem como se fosse desnecessário neste processo. 


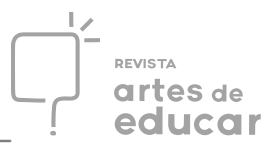

A escola deveria ser o lugar onde as possibilidades de se relacionar com o mundo fossem ampliadas e não reduzidas a uma única grande caixa com formas idênticas onde todos deverão se encaixar. Cada corpo é único e suas formas de se expressar: infinitas!

Um corpo brincante é o que deveria ser o desse aluno, divertindo-se enquanto aprende. É preciso renovar as maneiras de se olhar para os mesmos espaços, experimentar uma educação que vá além da sala de aula. O caminho das descobertas deveria colocar esse “corpo obediente" para experimentar a si mesmo e sentir alegria a cada passo desse trajeto: “[...] estamos em busca de uma pedagogia que brinque em conexão com a natureza, que seja libertária, gere felicidade” (TIRIBA, 2018, p.262).

\section{O corpo-potência no despertar do sujeito}

Conforme Tiriba (2017) a forma como o nosso corpo é, não é um acontecimento aleatório. Nosso corpo é a construção que permeia todas as nossas relações, sejam elas pessoais, sociais ou culturais. A história e a cultura não somente fazem parte do nosso corpo. Elas são o nosso corpo.

A construção do sujeito nunca é um processo límpido, cuja formação se dá somente por vias conscientes. As maneiros como nos relacionamos e nos expressamos refletem nosso ambiente cultural. "Desse modo, um sujeito encarna outros sujeitos em seu processo de construção, e não está totalmente livre na organização de seu campo de fala”. Entende-se com isso que o corpo sempre está embebido conscientemente ou inconscientemente por suas experiências (SETENTA, 2005, p.110).

Quando pensamos em corpo para criar potencialidades é necessário refletir sobre como acontece essa comunicação entre os corpos e o ambiente. Para Setenta (2005) quando o corpo se movimenta, a comunicação que é estabelecida evoca experiências, sentimentos e formas de estar no mundo. Esta comunicação é um estado de potência que desperta novos saberes.

Toda essa potência ao chegar na escola sofre um impasse. A escola alinhada com o capitalismo liberal, escolheu um modelo de ensino em que a cabeça pensante está em primeiro lugar e o corpo não tem o seu devido valor e muito menos a oportunidade de ser estudado ou sentido. Segundo Rios (2015) o grande desafio para nós, profissionais da educação, é 


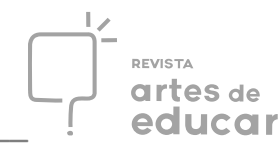

reconhecer que existe um conhecimento que surge a partir das experiências que o corpo inteiro pode proporcionar:

Para repensar e desenvolver a corporeidade é fundamental aprender a realidade corporal humana. Fica completamente descartado o hábito de entender o corpo a partir de elementos que vêm de fora. Essa leitura direta faz-se através da escuta da linguagem corporal. O corpo é falante, mas sua linguagem não deve ser científica, nem gramatical, muito menos matemática. Ela é, sem dúvida, cifrada, falta o intérprete [...] A corporeidade humana inspirada nessas linhas gerais precisa ser um desenvolvimento harmonioso como um concerto musical ou uma obra de arte em que nenhum aspecto ao alcance da criatividade de cada vida humana possa ser esquecido ou maltratado (SANTIN, 1993, p.67 apud RIOS, 2015, p.554).

Segundo Tiriba (2017) para que essa situação seja transformada, não basta simplesmente instalar programas de atividades corporais, tais como aulas de dança, educação física ou teatro na escola. Tudo isso é de extremo valor, mas a verdadeira mudança precisa ter como objetivo a subversão dos currículos tradicionais e mudanças nas rotinas que enclausuram os corpos, coibindo toda liberdade de movimento e manifestação das subjetividades.

Tiriba (2017) cita ainda a necessidade da escola ser pensada dentro de uma pedagogia sensível, que escute as necessidades dos alunos, e que essa sensibilização esteja presente nas práticas escolares, ecoando tanto na organização espacial como no acesso aos materiais didáticos.

\section{Disponibilidade para a experiência versus o programado}

“Espaço é pele, corpo, chão, cidade” (HISSA; NOGUEIRA, 2013, p.56). O olhar para a educação precisa considerar a história para que se possa entender como chegamos até aqui, mas não pode ficar parado no tempo. Educar deve ser para além do concreto, do escrito e do formato. Uma educação significativa deve falar do vivido, do que acontece, do que de fato está vivo dentro do espaço escolar e muitas vezes também fora dele.

Estar aberto e disponível para uma experiência, depende do quão livres estamos de nossas amarras: 
Não é que tenhamos perdido as mãos, mas sim que nos foram cortadas; não é que tenhamos perdido os gestos (e as maneiras), mas sim que tenham sido ignorados e menosprezados; não é que tenhamos perdido a língua, mas sim que nos ensinaram a falar em uma que não é a nossa. [...] talvez o que nos é dado como natural e necessário não seja nada mais do que aquilo que nos foi imposto e que ainda nos é imposto, na maioria das vezes, é claro, com a nossa colaboração entusiasta (LARROSA, 2018, p.42).

Toda existência está incorporada, ou seja, impressa nos corpos. Portanto, tem-se um corpo que flui com mais ou menos leveza a partir de suas memórias. Imagens podem nos mover ou nos paralisar.

Arroyo (2009), fala dessas imagens quebradas e que as tensões estão em nossas raízes. O autor traz importantes contribuições acerca do olhar para essas imagens corporais e chama atenção para essa escola que ainda mantém um imaginário de infância romantizado, em que a obediência é atrelada ao discente ideal. Desta forma, qualquer palavra ou atitude fora do perfil do aluno obediente, se torna um problema para a relação professor-aluno, fazendo com que tensões sejam acumuladas e o controle seja visto como o único elemento solucionador dos conflitos que surgem. O que acontece é que esta visão desconsidera o espontâneo, como se o imprevisto não existisse nas relações humanas.

Como agir quando o que acontece não é o que se espera? Há uma forma padrão de se sentar corretamente, há um horário especifico para correr... Tudo parece controlado e conduzido para um lugar confortável para o professor. $\mathrm{O}$ que buscamos aqui é dizer que quando o aluno move seu corpo e se coloca na direção oposta do que planejamos, ele pode estar criando uma oportunidade real do docente melhorar sua comunicação e conexão com seus educandos e com si mesmo.

A indisciplina dos alunos não precisa ser vista como um ato de arrogância. Esse corpo apenas reage ao que lhe é imposto com o que sente. É preciso abrir-se para ir além do que as palavras ou atitudes podem dizer. Um aluno não é um personagem plano, mas um ser multifacetado. "As vontades de estudar estão indissoluvelmente atreladas às possibilidades e limites de ser e aos horizontes do viver" (ARROYO, 2009, p.15). Por isso, somente entendendo as particularidades de cada um é que o conhecimento escolar pode se aproximar da realidade do aluno sujeito-humano. Enquanto nossa visão enxergar alunos-objetos, não faremos mais que exigir produções, quando devíamos prepará-los para a vida. 


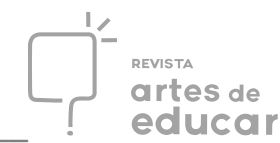

É isso que a gente tem feito, tanto na nossa vida de sujeitos que estão se formando enquanto pesquisadores quanto na própria pesquisa, indo aos lugares, ouvindo tudo desses lugares, como esses encontros cuidados enquanto encontros humanos de sujeitos que ao encontrar com outros sujeitos compreendem que não há objeto. O que há é que quando eu me encontro com o outro eu me alargo e nesse alargamento de mundo, eu me torno outra coisa, me torno humano, até mesmo na academia (de Mello, 2017, p.157)

Arroyo (2009), ainda acrescenta que quando as trajetórias de classe ou de raça são reconhecidas na prática educativa, uma outra dimensão de prática docente é reinventada. É necessário que o conhecimento não seja externado somente nas folhas de um papel, mas que também passe pelo corpo, pois é devido às subjetividades de cada ser, que o movimento podem ser vivenciado sob novas dimensões e perspectivas, descobrindo diferentes maneiras de se aprender. Ao atravessar o corpo, a experiência marca. E se a experiência marca, torna-se significativa e lembrada por toda uma vida. Isso é de fato uma outra definição para o ato de aprender. Por isso é importante refletir sobre como está o corpo do docente em suas práticas educativas, pois só assim ele poderá proporcionar para seus educandos esta possibilidade.

O medo de perder o controle leva professores a gritar com seus alunos para que façam como eles querem, ignorando o que os alunos são. E acaba-se ensinando para uma cabeça silenciada, como se o resto do corpo não existisse. Não se pode estimular um outro corpo a falar em suas múltiplas linguagens se ele (professor) não escuta seu próprio corpo e não conhece suas inúmeras possibilidades de sentir e se movimentar. Sendo assim, o que se vê é a redução da educação à um processo cognitivo, onde alunos e professores não se permitem sentir e viver a experiência educativa através do corpo em suas muitas formas de expressão.

Para gerar mudanças é preciso que a teoria e a prática estejam em sintonia. Para isso as práticas pedagógicas precisam tocar, motivar os corpos a fazerem movimentos em direção à criação, à transformação e à liberdade. Se os movimentos dentro da escola promovem vivências significativas capazes de gerar abertura, observamos que esses corpos se colocam mais disponíveis para experimentar outros caminhos.

Se o professor não tem tempo para vivenciar seu corpo e suas possibilidades, como entenderá que esse também é um tempo importante para seu aluno? É difícil trazer para nossa prática coisas que não são vivenciadas em nossos próprios corpos. É preciso entender que a 


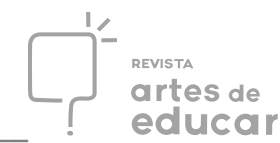

educação também muda a partir de uma sensação ou uma consciência adquirida por uma vivência. Existem saberes que só são adquiridos depois de anos de experiência.

Cada ser possui um corpo que lhe pertence. Mas será que ele se apropria realmente desse corpo? Exercita uma escuta sensível para poder acolher melhor o outro ou nem vê os dias atravessarem seu corpo de tão atarefado que está? Cada professor sabe o que o seu corpo sente? O que os alunos os fazem sentir? Se desafiam a descobrir outras possibilidades corporais de encontro para além daquelas que lhe foram ensinadas? Suas experiências pessoais terão validade frente aos conhecimentos teóricos?

O campo da educação é lugar de muitas dúvidas e questionamentos. Será dado o tempo que o professor precisa para descobrir possíveis respostas para tantas perguntas?

O sistema educacional quer que o professor inove, encontre uma forma de dar conta das demandas diárias e que os índices de avaliação de nossa educação sejam positivos. Mas, que condições são dadas aos profissionais da educação para que eles possam de fato trilhar um caminho lhes permita oferecer uma educação de qualidade?

Desviar da norma é construir e vivenciar um caminho de resistência e abertura para o novo, dentro da concepção de uma formação continuada e constante, que trate a educação como uma prioridade.

Como esperar que todos os professores atuem da mesma forma, se as suas experiências de vida e com sua turma são únicas? A luta deve ser pela liberdade de poder abrir caminhos. A sensação de controlar é uma ilusão e libertar-se é poder ver para além do emparedamento de corpos e conceitos. Na indiferença ninguém aprende.

\section{A corpo no processo de ensino-aprendizagem}

O processo de aprendizagem é descrito por Morgan (1977) como uma pequena ou grande modificação no comportamento, que seja resultado de uma experiência vivenciada. De acordo com o autor, a aprendizagem desenvolve novas aptidões a partir das relações socioambientais e de aspectos emocionais e neurológicos. Assim, quando pensamos em ensino-aprendizagem na educação, cabe à escola promover um pensamento que propicie diferentes experiências que possam ter um sentido para o aluno e que contribuam para o seu 


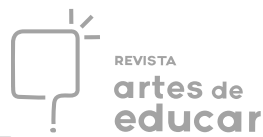

desenvolvimento. Dentro deste contexto, nos propomos a refletir sobre como o corpo e o movimento podem ser utilizados neste espaço como elementos potencializadores do saber.

Rios (2015) dizia ser inconcebível pensar em corporeidade sem pensar na relação com o outro. Para o autor, "Corporeidade sou eu. Corporeidade é você" (p.49). E é no espaço dessas inter-relações que a corporeidade se faz viva e latente.

Devemos entender o corpo e a mente como uma unidade dentro de um organismo vivo, em que o movimento é um elo intrínseco entre o mundo interno e externo de cada ser. Mas é importante questionar: Por que o corpo seria fundamental para o processo de ensinoaprendizagem?

Para Assmann (1998), dentro da concepção científica, o corpo é considerado a base fundamental para estruturar concepções vitais de estudo e da prática pedagógica. As ações do corpo marcam a sua presença no mundo externo. Portanto, ele não é um mero acessório atrelado à estímulos físicos. O corpo é a totalidade do ser, a integralidade do sujeito.

O corpo se transforma em corporeidade quando é superada a visão mecanicista e fragmentada do racionalismo cartesiano. A corporeidade é o corpo experienciado. É ela quem propicia ao corpo um diálogo significativo consigo mesmo e com o outro. É a partir da corporeidade que o processo cognitivo se inicia (RIOS, 2015).

O corpo é o intermediário da condição do sujeito no mundo. É através dele que se torna possível ter a percepção de tempo e espaço, por meio dos sentidos visuais, auditivos, olfativos e gustativos. Sem esses elementos seria impossível diferenciar as sensações do mundo. É a partir do corpo e da corporeidade que acontecem as construções simbólicas, a comunicação verbal e corporal e também o autoconhecimento (MARTINS, 2015).

Sendo assim, seria um erro não pensarmos no corpo e na corporeidade quando falamos de ensino-aprendizagem. Afinal, é pelo corpo que se concebe toda a nossa experiência enquanto sujeitos e indivíduos sociais. O corpo é potência pela sua capacidade de aprender e se reinventar. Quando este corpo é anulado, valorizando-se somente o intelecto por suas vias cognitivas, todo o resto é perdido, o que empobrece todo tipo de experiência.

O que enriquece nossas vivências é a experimentação do corpo por uma via mais livre e consciente. Toda uma gama de possibilidades de movimento que um corpo pode criar e provocar não podem ser quantificadas em números. Quando a corporeidade é colocada como parte do processo educativo, reconhecendo que somos sujeitos sensíveis, a recompensa é infinita. Aprendizados assim atravessam os portões da escola e afetam de forma positiva a 


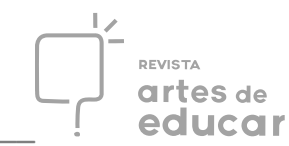

relação com o outro e a forma como este indivíduo passa a ver o mundo e a se relacionar com ele.

\section{Considerações finais}

A potência contida no corpo de cada ser é elemento imprescindível para gerar aprendizagens significativas que estejam em sintonia com o mundo que nosso aluno vive e encontra fora da escola. Conscientes de que "[...] cada corpo é historicamente construído conforme os sonhos e receios de sua época e cultura” (SANT'ANNA, 2005, p. 127), entendemos que os saberes nunca deveriam ser fixos e obedecer a um sistema de reprodução. Já que cada época apresenta características próprias, o conhecimento deveria se transformar com o tempo. É para isso que deveríamos estar trabalhando: na renovação dos saberes.

Tomados por uma velocidade que atropela vontades de experimentar e a capacidade criativa, o que presenciamos são corpos anulados, sedentários e esquecidos de suas vontades e de seu amor próprio. O que ocorre de forma mecânica só é interrogado pela vivência, capaz de sensibilizar e fazer com que se tenha vontade de correr o risco de ir além das zonas de conforto.

O corpo é a ponte de contato com o mundo externo. Viver dentro de nossa potência promove um resgate sobre esse corpo que se dá conta que tem escolha e que pode decidir sobre o seu caminhar ao invés de apenas se deixar levar. O adoecimento está impresso nos corpos, fazendo-os pesar como uma âncora e aos poucos perder sua mobilidade e consequentemente sua pulsão de vida.

Alunos e professores só conseguirão se libertar desse lugar onde representam "peças de uma engrenagem", a partir da sensibilização e de atividades que os façam entrar em contato com as múltiplas linguagens pelas quais seu corpo pode se expressar, descobrindo por meio delas, a potência para transformar que existe dentro de cada um de nós.

Dizer sim ao que faz bem ao corpo equilibra nossas emoções com experiências positivas e nos desperta para uma outra forma de viver, onde as forças dos seres se somam, aproximando-os de sua natureza humana. 


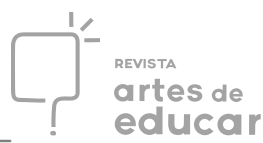

Um professor que reconhece sua potência passa a descobrir, ousar, aproveitar o encontro com seus alunos, criar novas práticas pedagógicas e desfrutar de um tempo que antes parecia correr em direção ao desejo da aposentadoria. Quanto mais consciência de sua potência, menos precisará usar da hierarquia, pois já não haverá mais a necessidade de controlar.

Um professor potente, potencializa também seus alunos. E os corpos na escola não serão mais obrigados a se ajustar e se modelar a uma forma quadrada de bolo como se a diversidade e a individualidade não existissem. Quando permitimos que cada um seja o que consegue ser, a aprendizagem acontece por uma via mais natural. Os seres se encontram e espontaneamente trocam saberes. Quando a prática educativa se torna menos comparativa e hierarquizante, os indivíduos podem descobrir diversas formas de aprender em um ambiente de paz, que respeita ritmos diferentes de aprendizagem e a pluralidade que se apresenta no espaço escolar.

A potência está em viver, ter calma para reparar nas coisas a nossa volta, ter consciência da nossa força e do que nos faz bem. A potência não está em gastar toda a nossa energia para sobreviver a mais um dia e nem em ter nossas identidades desconectadas da vida que vivemos.

"Interessa-nos a ideia de que a invenção está em qualquer lugar. Ela é "a potência do homem comum” (PELBART, 2003, p. 23). Assim, há uma positividade imanente na potência da vida".

Se conseguimos diminuir a velocidade para poder enxergar o que de fato importa, os gestos de nossos corpos também terão a tranquilidade necessária para viver suas possibilidades e potências para existir e viver educação. Ao renovar o olhar sobre o processo de aprender, tornando-o mais humano, professores e alunos moverão seus corpos de outras formas, transformando pouco a pouco as práticas pedagógicas em momentos de prazer e leveza. Assim, o aprender perderá a sua característica obrigatória e finalmente estará em sintonia com a nossa essência que é construir aldeias de saberes e não prisões para nossos corpos. 


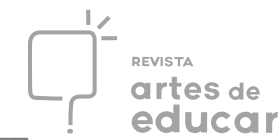

\section{REFERÊNCIAS}

AGGIO, Juliana. Prometeus Filosofia em Revista. Departamento de Filosofia Universidade Federal de Sergipe, ano 2, nº 3, jan./jun. 2009.

ALMEIDA, Danilo. Educação: o silêncio do corpo - $2^{\circ}$ Seminário de Educação na UNESP de Franca. Maio, 2009.

ARROYO, Miguel. Imagens Quebradas. Petrópolis: Vozes, 2009.

ASSMANN, H. Metáforas novas para reencantar a educação: epistemologia e didática. 2. ed. Piracicaba: Unimep, 1998.

BRANDÃO, Carlos. Saber para si, saber com os outros. In: COSTA, Renato; CALHÁU, Socorro (orgs). “...e uma EDUCAÇÂO pro povo, tem?”. Rio de Janeiro: Editora Caetés, 2010.

Curricular do Ensino Fundamental. Belo Horizonte: SEE/MG, 2005.

DAMÁSIO, António. Em busca de Espinosa: prazer e dor na ciência dos sentimentos.

São Paulo: Companhia das Letras, 2004.

DAUSTER, Tania (org). Antropologia da Educação - Um saber de fronteira. Rio de Janeiro: Forma \& Ação, 2007.

DE MELLO, Marisol. O Amor em Tempos de Escola. São Paulo: Pedro \& João Editores, 2017.

DESCARTES, René. Meditações - Os pensadores. São Paulo: Abril Cultural, 1983.

DIMENSTEIN, Gilberto; ALVES, Rubem. Fomos maus alunos. Campinas, SP: Papirus 7 mares, 2008.

FREIRE, J. B. Educação de corpo inteiro. São Paulo: Editora Scipione, 1989.

FREGONEIS, Bonfitto. O Sujeito-Corpo nas Representações de Si Revista Cena. Porto Alegre, n. 26, p. 6-19 set./dez. 2018. Disponível em: http://seer.ufrgs.br/cena

GAIA, Adroaldo. A reinvenção dos corpos: Por uma pedagogia da complexidade.

Sociologias, 15, 250-272. Acesso em 2/12/2019 http://www.scielo.br/scielo.php?pid=S1517$45222006000100009 \&$ script=sci_abstract\&tlng=pt.

GORDON, Mary. O Poder da Empatia. In: CAVOUKIAN, Raffi; OLFMAN, Sharna (org). Honrar a criança: como transformar este mundo. São Paulo: Instituto Alana, 2015.

GRUPO ATOS UFF. Fio Solto: Que escola você deseja? São Paulo: Pedro \& João Editores, 2016. 
HISSA, c. e. v.; NOGUEIRA. Cidade-corpo rev. UFMG, Belo Horizonte, v. 20, n.1, p.54-77, jan./jun. 2013.

INFORSATO, E. C. A educação entre o controle e a libertação do corpo. In: MOREIRA, W. W. (Org.). Século XXI a era do corpo ativo. Campinas: Papirus, 2006.

LARROSA, Jorge. Esperando não se sabe o quê: sobre o ofício de professor. Belo Horizonte: Autêntica Editora, 2018.

LAURO, Rafael. Foucault - Disciplina e Biopolítica. Razão Inadequada. Disponível em: <https://razaoinadequada.com/2019/06/30/foucault-disciplina-e-biopolitica/>

LAURO, Rafael. Afetos (Bio) Políticos - Coragem. Razão Inadequada. 16 de novembro de 2018. Disponível em: <https://razaoinadequada.com/2018/10/31/afetos-biopoliticoscoragem/>

LE BRETON, David. A sociologia do corpo. Petrópolis: Editora Vozes, 2006.

MACEDO, E. Esse corpo das ciências é o meu? In: AMORIM, A. C. et al Ensino de

Biologia: conhecimentos e valores em disputa. Niterói: Eduff, 2005. p.131-140.

MEIRELES, Maximiano. O sensível na formação docente: Com textos de uma experiência formativa. Formação de Professores, complexidades e trabalho docente. PUC. 2015.

MARTINS, Bruno. Oprimidos da Pedagogia: de Paulo Freire à educação democrática. São Paulo: Nibelungo, 2014.

MARTINS, Ernesto. A corporeidade na aprendizagem escolar: Entrelaços fenomenológicos do pensar e agir. Educar em Revista. Curitiba, Brasil.Editora UFPR, n. 56, p. 163-180, abr./jun. 2015.

MERLEAU-PONTY, M. Fenomenologia da percepção. Trad. Carlos Alberto R. de Moura. São Paulo: Martins Fontes, 1996.

MINAS GERAIS. Secretaria de Estado da Educação. Educação Física: proposta

MORGAN, Clifford T. Introdução à Psicologia. São Paulo: McGraw-Hill do Brasil, 1977.

MOYZÉS, Maria; MOTA, Maria.V.S. Sensibilização e conscientização corporal do professor. In: Convenção Brasil Latino América, Congresso Brasileiro e Encontro Paranaense de Psicoterapias Corporais. Foz do Iguaçu. Anais. Centro Reichiano, 2004.

NÓBREGA, Terezinha. Corpo, Percepção e Conhecimento. In: Merleau-Ponty: Estudos de Psicologia. Rio Grande do Norte, V.13, n.2, p. 141-148, ago. 2008.

OLIVIER, Giovanina. Um olhar sobre o esquema corporal, a imagem corporal, a consciência corporal e a corporeidade. 1995. Tese (Mestrado em Educação Motora da Faculdade de Educação Física da Universidade Estadual de Campinas). Disponível em: < 


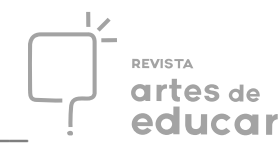

http://www.bibliotecadigital.unicamp.br/document/?code=vtls000095484> Acesso em: 5/10/19.

PELBART, Peter. Vida capital: ensaios de biopolítica. São Paulo: Iluminuras, 2003.

ROBERTI. Daniel. Um olhar sobre a "vivência" através do seu autor: Conceitos e traduções na obra de Vigotski. Fractal: Revista de Psicologia, v. 31, n. 1, jan.-abr. 2019.

RODRIGUES, Neidson. Educação: da formação humana à construção do sujeito ético. Educação e Sociedade. Campinas, XXII, n. 76, p. 232-257, out, 2001.

RIOS, Fabiola. A importância do corpo no processo de ensino e aprendizagem. Evidência, Araxá, v. 11, n. 11, p. 49-58, 2015.

SANT'ANNA, Denise. Horizontes do corpo. In: BUENO, M. L.; CASTRO, A. L. (Org.). Corpo território da cultura. São Paulo: Annablume, 2005.

SANTIN, Silvino. Perspectivas na visão da corporeidade. In: GEBARA, Ademir et al. Org. Wagner Wey Moreira. Educação Física e esportes: perspectivas para o século XXI. 5 ed. Campinas, SP: Papirus, p. 51-69, 1993.

SETENTA, Jussara. Da potência ao ato. Da ideia para a ação: O corpo em estado de definição. Cognitivo- Estudos. Revista eletrônica de filosofia,2005.

SANTOS, Elisama. Educação Não Violenta: Como estimular autoestima, autonomia, autodisciplina e resiliência em você e nas crianças. Rio de Janeiro/São Paulo: Paz \& Terra, 2019.

SILVA, Monique; OLIVEIRA, Maria. Ensaio em defesa da leveza, do sensível e da sensibilidade na pesquisa em educação. Educação e Filosofia, v. 30, n. 60, p. 775-798, jul./dez. 2016.

TALOMONI, Ana Carolina; FILHO, Claudio. Corpo e Educação: As representações de professores no ensino fundamental. VII ENPEC. Encontro Educacional de Pesquisas em educação e ciências, 2009.

TIRIBA, Lea. Pré-Escola Popular buscando caminhos, ontem e hoje. São Paulo: Cortez: 2018.

TIRIBA, Lea. Na Escola: o corpo silenciado.12 de janeiro de 2017. Disponível em: <https://issuu.com/paralapraca/docs/o_corpo_silenciado $>$

TIRIBA, Léa. Educação Infantil como direito e alegria: em busca de Pedagogias ecológicas, populares e libertárias. $1^{\text {a }}$ edição. São Paulo: Paz e Terra, 2018.

VIANNA, Angel; CASTILHO, Jacyan. Percebendo o corpo. In: GARCIA, Regina Leite (org.). $O$ corpo que fala dentro e fora da Escola. Rio de Janeiro: DP\&A, 2002. 
VIGOTSKY, Lev. Psicologia da Arte. Tradução: Paulo Bezerra. São Paulo: Martins Fontes, 1999.

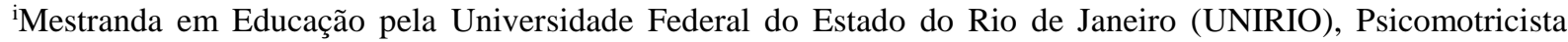
Educacional, Graduada em Educação Física pela Universidade Federal do Rio de Janeiro (UFRJ). Participante do grupo de estudos GITAKA (Infâncias, tradições ancestrais e cultura ambiental). Petrópolis-RJ/Brasil. mailto:mari2lopez@hotmail.com ORCID: https://orcid.org/0000-0002-9719-4520

ii Mestranda em Educação pela Universidade Federal do Estado do Rio de Janeiro (UNIRIO). Graduada em Dança pela Universidade Federal de Viçosa (UFV). Participante do grupo de estudos GFPPD (Formação de professores, Pedagogias Decoloniais e Interculturalidade). Rio de Janeiro-RJ/Brasil. mailto:gracielegaldinoo@gmail.com ORCID: https://orcid.org/0000-0001-5457-2061

${ }^{3}$ Lei $\mathrm{n}^{\mathrm{o}} 12.527 / 2011$ regulamenta o direito constitucional de acesso às informações públicas. Essa norma entrou em vigor em 16 de maio de 2012 e criou mecanismos que possibilitam, a qualquer pessoa, física ou jurídica, sem necessidade de apresentar motivo, o recebimento de informações públicas dos órgãos e entidades. Disponível em: http://www.acessoainformacao.gov.br/assuntos/conheca-seu-direito/a-lei-de-acesso-a-informacao Acesso em: 23 de janeiro, 2020.

${ }^{4}$ Trecho retirado de: A importância do corpo no processo de ensino aprendizagem. RIOS. Fabíola Teixeira Araujo $^{1} I N$ : SANTIN, S. Perspectivas na visão da corporeidade. In: GEBARA. Ademir et al. Org. Wagner Moreira. Educação Física e esportes: Perspectivas para o século XXI. 5 ed. Campinas, SP, Papirus1993. 